\title{
Learning at old age: a study on winter bees
}

\author{
Andreas Behrends ${ }^{1}$ and Ricarda Scheiner ${ }^{2 *}$ \\ ' Institut für Ökologie, Technische Universität Berlin, Berlin, Germany \\ 2 Institut für Biochemie und Biologie, Universität Potsdam, Potsdam, Germany
}

\author{
Edited by: \\ Martin Giurfa, \\ Université Paul Sabatier - Toulouse III, \\ France \\ Reviewed by: \\ Jean-Christophe Sandoz, \\ Université Paul Sabatier - Toulouse III, \\ France \\ Olav Rueppell, \\ The University of North Carolina at \\ Greensboro, USA \\ *Correspondence. \\ Ricarda Scheiner, \\ Institut für Biochemie und Biologie - \\ Zoophysiologie, Universität Potsdam, \\ Karl-Liebknecht-Str. 24-25, Haus 26, \\ D-14476 Potsdam, Germany. \\ e-mail: ricarda.scheiner-pietsch@ \\ uni-potsdam.de
}

Ageing is often accompanied by a decline in learning and memory abilities across the animal kingdom. Understanding age-related changes in cognitive abilities is therefore a major goal of current research. The honey bee is emerging as a novel model organism for age-related changes in brain function, because learning and memory can easily be studied in bees under controlled laboratory conditions. In addition, genetically similar workers naturally display life expectancies from 6 weeks (summer bees) to 6 months (winter bees). We studied whether in honey bees, extreme longevity leads to a decline in cognitive functions. Six-month-old winter bees were conditioned either to odours or to tactile stimuli. Afterwards, long-term memory and discrimination abilities were analysed. Winter bees were kept under different conditions (flight/no flight opportunity) to test for effects of foraging activity on learning performance. Despite their extreme age, winter bees did not display an age-related decline in learning or discrimination abilities, but had a slightly impaired olfactory long-term memory. The opportunity to forage indoors led to a slight decrease in learning performance. This suggests that in honey bees, unlike in most other animals, age per se does not impair associative learning. Future research will show which mechanisms protect winter bees from age-related deficits in learning.

Keywords: olfactory learning, tactile learning, honey bee, longevity, ageing

\section{INTRODUCTION}

In the Western world, the human population grows continually older. A side-effect of the aging population is an increase in agerelated diseases such as Alzheimer's disease and Parkinson's disease, which ultimately result in a decline of cognitive functions. This makes the study of age-related changes in cognitive functions a major goal of this century.

Over the last years, we have gained important insight into ageing processes of the brain through a number of vertebrate and invertebrate models. Most experiments on learning at old age have been conducted in organisms like the fruit fly Drosophila melanogaster (Tamura et al., 2003; Grotewiel et al., 2005), the nematode Caenorhabditis elegans (Murakami and Murakami, 2005) and the mouse Mus musculus (Gower and Lamberty, 1993; Unno et al., 2007). In these animals, ageing of the central nervous system is mostly related to the age of the individuals. Although the plasticity of ageing and cognitive decline is of major interest, we lack models in which ageing processes in the brain are decoupled from chronological age.

The honey bee is beginning to be recognized as a new model for studying the biology of aging, because it offers a number of advantages. Life span of honey bee workers can range between 6 weeks and more than 6 months. Summer workers usually live up to 6 weeks, whereas winter bees become 6 months old and older (Omholt and Amdam, 2004; Remolina and Hughes, 2008). A fascinating aspect of this plasticity is that all of these workers could have similar genotypes, because life span in honeybee workers is mostly regulated by environmental factors (Winston, 1987; Seeley, 1995). These characteristics make honey bees an excellent tool for testing candidate genes for ageing and regulation of lifespan (for review see Rueppell et al., 2004) as identified in other model organisms (Keller and Jemielity, 2006).
Honey bee ageing is very plastic. After nursing the brood and the queen in the hive, a task which is accompanied by slow senescence, they forage outside the hive for pollen, nectar, water and propolis, which leads to rapid senescence (for review see Amdam and Page, 2005). But foragers are capable of reverting to nursing tasks if the nurse bees have been removed from a colony, and nurse bees can be induced to forage precociously (Robinson et al., 1989, 1992; Huang and Robinson, 1996; Behrends et al., 2007). Whereas the former procedure increases life span, the later reduces life span, because the foraging duration of a honey bee is more or less fixed. Therefore, bees initiating foraging early in life will live shorter, while individuals starting to forage late will live longer (GuzmánNovoa et al., 1994; Tofilski, 2000; Page and Peng, 2001; Rueppell et al., 2008, 2009).

Another advantage of honey bees is their unique behavioural repertoire including tactile, olfactory and visual learning which can be studied under controlled laboratory conditions and in the field (for review see Menzel and Müller, 1996; Giurfa, 2007; Srinivasan, 2010). This allows a detailed analysis of brain functions at all ages. Taken together, these characteristics make the bee particularly interesting for the study of age-related changes in brain functions and their underlying mechanisms.

Winter bees are workers that emerge shortly before the end of the foraging period and survive up to 6 months and longer (for review see Remolina and Hughes, 2008). They stay in a cluster inside the hive and engage in thermoregulation and queen-care until the start of the next foraging period. Winter bees do not hibernate but stay active in the hive throughout the winter time. Therefore, winter bees or diutinus bees provide a unique life form, since their physiological properties closely resemble those of young summer hive bees, although their age and experience is extremely 
different. Thus winter bees have well-developed hypopharyngeal glands and low titres of juvenile hormone (Fluri et al., 1982), which is a releaser of foraging behaviour at high concentrations (Schulz et al., 2002). In addition, winter bees have high titres of vitellogenin. This protein is an egg yolk precursor which is used for producing brood food and, at the same time, protects bees from oxidative cellular damage (Seehuus et al., 2006a). Finally, the transition from in-nest behaviour to foraging is delayed by several months in winter bees.

To analyse associative learning, different paradigms for conditioning under controlled laboratory conditions have been developed (Kuwabara, 1957; Bitterman et al., 1983; Menzel and Müller, 1996; Erber et al., 1997; Giurfa and Malun, 2004; Giurfa et al., 2009). We decided to study classical olfactory conditioning of the proboscis extension response (PER) and operant tactile conditioning (Bitterman et al., 1983; Erber et al., 1997). Classical olfactory conditioning might reveal deficits in the olfactory system commonly associated with old-age diseases like Alzheimer's disease (Wilson et al., 2009). Tactile learning, which requires more activity on part of the bee, was chosen to test for age-dependent deficits in the motor system, such as frequently found in patients with Parkinson's disease (Chung et al., 2003).

A number of tactile and olfactory conditioning experiments using summer bees maintained under different hive conditions have shown that chronological age has no effect on associative learning in older worker bees (Behrends et al., 2007; Rueppell et al., 2007; Scheiner and Amdam, 2009). In those experiments, social role determined learning performance rather than chronological age. However, bees in those experiments were much younger than winter bees, on average no older than 50 days.

Associative learning of the proboscis extension response is strongly determined by individual evaluation of the sucrose reward. Bees showing proboscis extension to stimulation of the antennae with low sucrose concentrations learn tactile and olfactory cues faster than bees with low responsiveness to sucrose (Scheiner et al., 1999, 2001a,b, 2003, 2005). To determine whether learning differences were solely a result of differences in responsiveness to sucrose, we separately tested for this parameter.

In our study, we analysed the associative learning, memory and discrimination abilities of winter bees aged between 160 and 180 days. We compared their learning performance to that of much younger summer bees performing different social tasks and to that of winter bees of an indoor flight room. The latter had the opportunity to forage for pollen, sucrose solution and water. We thus wanted to answer the question if the learning performance of outdoor winter bees is related to their inability to perform flights over the cold winter period.

\section{MATERIALS AND METHODS OUTDOOR WINTER BEES}

Experiments were performed between winter 2006 and summer 2009 in Berlin. Our outdoor overwintering colony contained approximately 7,000 bees (Apis mellifera carnica). At the end of the foraging period, we marked 1,000 newly emerged bees at the thorax with paint (shellack mixed with colour pigments) and introduced them to this colony. This allowed us to identify their age the next spring. Bees were 160-180 days old when tested in the behavioural assays and presumably had never foraged, because we introduced the bees just before the temperatures dropped to below $8^{\circ} \mathrm{C}$ and collected the bees from the combs before temperatures allowed foraging activity the next spring. Most of the bees tested for learning abilities had full guts when we mounted them. Because bees can take cleansing flights in the winter period to defecate, this is a further indicator that the climatic conditions did not allow these bees to leave the hive in the winter before we collected them. The bees introduced into the overwintering colony stemmed from a naturally mated queen.

\section{INDOOR WINTER BEES}

At the end of the foraging period, we placed a small colony of about 3,000 bees in a flight room $(5 \mathrm{~m} \times 4 \mathrm{~m})$ maintained at a 12:12 light/dark cycle at $28^{\circ} \mathrm{C}$ and $45 \%$ humidity. Bees could daily engage in flight and foraging activities on artificial pollen, water and sucrose feeders. For the behavioural assays we collected bees that were engaged in flight after presenting a pollen source near the hive entrance.

The indoor winter bees did not have the same genetic origin as the outdoor winter bees but also came from a naturally mated queen. Because we measured individual gustatory responsiveness prior to conditioning, we could nevertheless compare the learning performance of the two groups of bees. Gustatory responsiveness is the most important determinant of associative learning performance (for review see Scheiner et al., 2004) and bees of different patrilines (Scheiner and Arnold, 2010) and bees of highly different genetic strains (Scheiner et al., 2001a,b) only differed in their learning performance when the gustatory responsiveness of the patrilines or strains differed. A joint analysis of gustatory responsiveness and associative learning performance can thus explain whether possible learning differences are solely a result of differences in sensory responsiveness or whether they are "real" differences in the learning/memory system.

\section{SUMMER BEES}

To compare the learning performance of winter bees with that of summer bees, we collected nurse bees and foragers from a garden colony containing about 7,000 bees. Because bees have a high probability of being nurse bees when they are 6 days old, we only collected bees of this age group which were putting their heads in a cell with brood. Only bees with intact wings and furry coat on their thorax were regarded as nurse bees. Foragers were collected from the hive entrance after returning to the colony. We only used nectar foragers for this experiment. Foragers were not collected according to age, because (1) they were to represent a mixed sample of bees which is typically used in conditioning experiments and because (2) age has no effect on learning performance in foragers (Behrends et al., 2007; Scheiner and Amdam, 2009). The bees tested in this experiment stemmed from a naturally mated queen, which however, was different from that used for producing the winter bees.

\section{PREPARATION OF BEES FOR CONDITIONING}

After collecting the bees individually in glass vials, they were cooled in a refrigerator until they showed first signs of immobilization. Then they were mounted on metal tubes with a tape between 
head and thorax and one tape on the abdomen to prevent stinging. Afterwards the bees rested for $1 \mathrm{~h}$ in a humidified chamber (Bitterman et al., 1983; Scheiner et al., 1999). For tactile learning, their complex eyes were occluded with black acrylic paint prior to resting to block visual input (Erber et al., 1997).

\section{GUSTATORY RESPONSIVENESS}

Before conditioning, we tested all bees for gustatory responsiveness using the proboscis extension response (PER). In time intervals of $2 \mathrm{~min}$ the bees were tested for PERs to a series of water and increasing sucrose concentrations presented to both antennae. We used the following concentrations of $0 ; 0.1 ; 0.3 ; 1.0 ; 3.0 ; 10$ and $30 \%$ sucrose (weight/volume). During each stimulation we applied a droplet of $1 \mu \mathrm{l}$ sucrose solution to the tips of the antennae and recorded if the bee displayed the PER. Afterwards, a gustatory response score (GRS) was calculated for each bee. It comprises the sum of all PERs during the assay. The GRS ranged between 0 and 7 . The score of 7 indicates a highly responsive bee, a score of 0 implies no responsiveness to sucrose (Scheiner et al., 2004).

\section{OLFACTORY CONDITIONING}

After measuring gustatory responsiveness, bees with a GRS $>0$ were tested for olfactory acquisition performance by conditioning the PER to carnation odour. Prior to the conditioning procedure the bees were tested for their spontaneous response to the conditioned odour carnation and the new odour stimulus cineole with an inter-trial interval of $5 \mathrm{~min}$. Bees displaying spontaneous proboscis extension to either odour were discarded. For conditioning, a bee was placed in a constant air stream for $8 \mathrm{~s}$ and was stimulated with $5 \mathrm{ml}$ of an odour/air mixture delivered by a $20-\mathrm{ml}$ syringe $(2 \mu \mathrm{l}$ odour on a small piece of filter paper) in front of the bee.

The first conditioning trial started 5 min after the spontaneous response tests. This was done by eliciting the PER with a droplet of $30 \%$ sucrose solution while the bee experienced the carnation odour. The bee was allowed to drink about $1 \mu$ of the sucrose solution as a reward. If the bee did not respond to the sucrose stimulus, it was discarded from further conditioning. If the bee responded with spontaneous PER to the odour stimulus in the first trial it was also discarded. At each of the six conditioning trials it was recorded whether the bee displayed a conditioned PER. An acquisition score was calculated which ranged from 0 to 5 . It comprises the sum of all conditioned PERs. Five minutes after the conditioning procedure we tested the bees' responses to the new odour cineole and then the response to the conditioned odour carnation. The inter-trial interval was again $5 \mathrm{~min}$. Tests for the new odour and for the conditioned odour were repeated 24 and $48 \mathrm{~h}$ after conditioning.

\section{TACTILE CONDITIONING}

Tactile conditioning was performed similarly to olfactory conditioning. Only bees with a GRS $>0$ were used for conditioning. The tactile stimulus consisted of a $3 \times 4 \mathrm{~mm}$ copper plate. The tactile pattern which was presented as the conditioned stimulus was engraved vertically and the pattern which was used as an new stimulus was engraved horizontally. Prior to the conditioning procedure, bees were tested for their spontaneous responses to the plate when it was placed in the scanning range of their antennae.
The inter-trial interval was 5 min throughout the experiment. Six conditioning trials were performed. At each conditioning trial, the plate with the vertical pattern was brought into the scanning range of the bees' antennae with the help of a micromanipulator. While the bee scanned the surface of the plate we elicited the PER by applying a droplet of sucrose solution to the antennae of the bee. Once the bee extended its proboscis it was allowed to drink approximately $1 \mu \mathrm{l}$ of sucrose solution. If the bee touched the plate with its proboscis, the plate was cleaned with $70 \%$ ethanol and subsequently with water. Testing conditioned responses without reward was performed $5 \mathrm{~min}$ after the last of the six conditioning trials. First, we tested the response to the new horizontal pattern and $5 \mathrm{~min}$ later the response to the conditioned vertical pattern. This test was repeated 24 and $48 \mathrm{~h}$ later to test for short-term, midterm and long-term memory.

\section{STATISTICS}

For sucrose-concentration response curves, learning curves of olfactory and tactile conditioning and graphic displays of memory tests, percentages of conditioned PERs were calculated (PASW 18.0). Numbers of bees' responses in the discrimination and memory tests were compared using two-tailed Fisher Exact Probability Tests (GraphPad Instat 3). Acquisition scores are a measure of overall learning success. They represent the total number of conditioned responses during the acquisition phase (Scheiner et al., 1999). Gustatory response scores are a measure for gustatory responsiveness (Scheiner et al., 2004). Both types of scores were not distributed normally as revealed by Kolmogorov-Smirnov Tests. Therefore, we compared the respective scores between two groups using twotailed Mann-Whitney $U$ Tests. When more than two groups were compared, we performed nonparametric ANOVA (Kruskal-Wallis $H$ Tests) and used Dunn's Test as post hoc test to compare pairs. All tests were two-tailed.

\section{RESULTS}

\section{OLFACTORY ACQUISITION AND GUSTATORY RESPONSIVENESS OF OUTDOOR WINTER BEES AND SUMMER BEES}

Despite their high chronological age, outdoor winter bees showed no impairment of associative olfactory learning and displayed a typical olfactory PER learning curve, similar to that of summer foragers or nurse bees (Figure 1B). To test whether outdoor winter bees differed significantly in their classical olfactory learning performance from summer bees, we compared the acquisition scores of winter bees with those of nurse bees and of summer foragers. Acquisition scores comprise the total number of conditioned responses during conditioning. Winter bees did not differ in their acquisition scores from summer nurse bees or from summer foragers (Figure 1D; $H=3.90, p=0.15, n_{\text {summer nurse bees }}=35$, $n_{\text {summer foragers }}=20, n_{\text {outdoor winter bees }}=30$, Kruskal-Wallis $H$ Test $)$.

Because individual olfactory learning performance is strongly dependent on gustatory responsiveness (for review see Scheiner et al., 2004), we also compared this factor between the different groups. The sucrose-concentration response curve of winter bees was intermediate between that of summer nurse bees and that of summer foragers (Figure 1A). Gustatory response scores (GRS), which are a measure of gustatory responsiveness and were used for statistical comparison, differed significantly between the three 


\section{A Gustatory responsiveness}

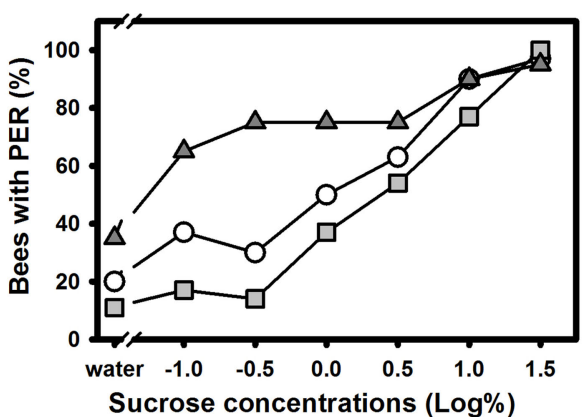

C

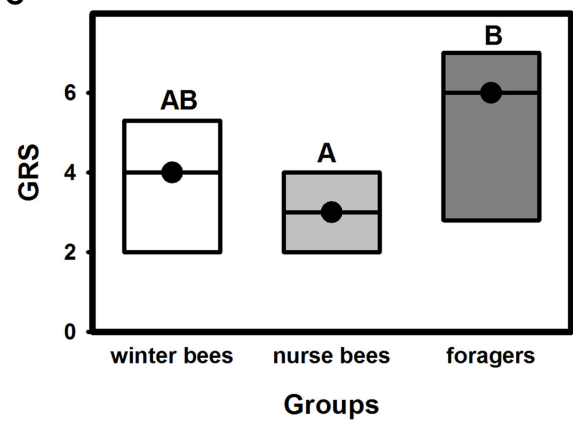

FIGURE 1 | Gustatory responsiveness and olfactory acquisition of outdoor winter bees, summer nurse bees and summer foragers. (A) Sucroseconcentration response curves of outdoor winter bees, summers nurse bees and summer foragers. The $x$-axis displays the sucrose concentration offered to the antennae of each bee. The $y$-axis shows the percentage of bees showing the proboscis extension response (PER). (B) Olfactory acquisition curves of outdoor winter bees, summer nurse bees and summer foragers. The $x$-axis displays the conditioning trials. The $y$-axis shows the percentage of bees showing conditioned

\section{B Olfactory acquisition}

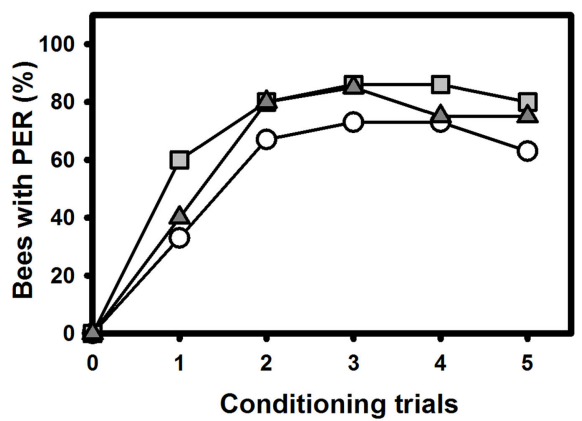

○

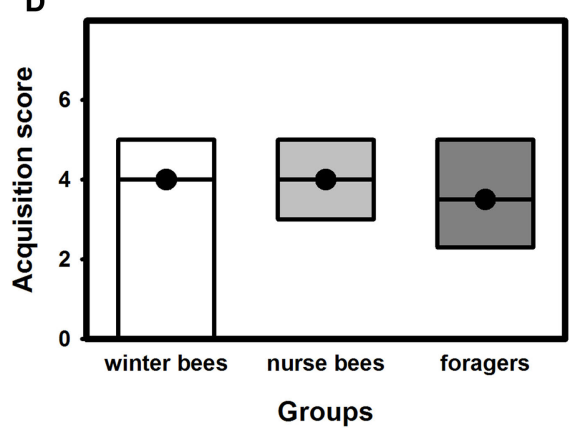

PER. (C) Gustatory response scores (GRS) of outdoor winter bees, summer nurse bees and summer foragers. The $x$-axis displays the different groups. The $y$-axis shows median GRS (dots) and 25\% (lower line) and 75\% (upper line) quartiles. Groups with different letters differ significantly from each other. For statistics see text. (D) Olfactory acquisition scores of outdoor winter bees, summer nurse bees and summer foragers. The $x$-axis displays the different groups. The $y$-axis shows median acquisition scores (dots) and 25\% (lower line) and $75 \%$ (upper line) quartiles. The groups did not differ from each other. groups (Figure 1C; $H=9.61, p \leq 0.01$, Kruskal-Wallis $H$ Test). However, outdoor winter bees did not differ in their GRS from summer nurse bees $(p>0.05)$ or from summer foragers $(p>0.05)$. But foragers were significantly more responsive than nurse bees ( $p \leq 0.01$, Dunn's Test).

\section{OLFACTORY MEMORY AND DISCRIMINATION OF OUTDOOR WINTER BEES AND SUMMER BEES}

After training, we tested how well the bees discriminated between the conditioned odour carnation and the new odour cineole at $5 \mathrm{~min}, 24$ and $48 \mathrm{~h}$ after conditioning. Of the outdoor winter bees surviving the 48-h test, individuals responded significantly more often to the conditioned odour carnation than to the new odour cineole at all time points after conditioning and thus demonstrated significant discrimination (Figure 2; 5 min: $p \leq 0.001,24$ h: $p \leq 0.05$, 48 h: $p \leq 0.01, n_{\text {outdoor winter bees }}=27$, Fisher Exact Probability Test).

Of the nurse bees surviving the 48 -h test, individuals responded significantly more often to the conditioned odour carnation than to the new odour cineole $5 \mathrm{~min}$ and $48 \mathrm{~h}$ after conditioning and thus displayed significant discrimination, but not $24 \mathrm{~h}$ after conditioning (Figure 2; 5 min: $p \leq 0.001,24 \mathrm{~h}: p=0.06,48 \mathrm{~h}: p \leq 0.001, n_{\text {summer }}$ $=29$, Fisher Exact Probability Test).

Five minutes and $24 \mathrm{~h}$ after conditioning, nurse bees did not differ from winter bees in their responses to the conditioned odour or to the new odour ( 5 min CS: $p=0.19$, new odour: $p=0.72$, 24 h CS: $p=0.58$, new odour: $p=0.16$ ). Interestingly, nurse bees responded significantly more often to the conditioned odour than winter bees $48 \mathrm{~h}$ after conditioning ( $p \leq 0.05)$, while not differing in their responses to the new odour $(p=0.73$, Fisher Exact Probability Test). They apparently developed a better olfactory long-term memory than winter bees.

Foragers surviving the 48 -h test displayed significant discrimination between the two odours only $48 \mathrm{~h}$ after conditioning (Figure 2; $p \leq 0.01)$ but not $5 \mathrm{~min}(p=0.66)$ or $24 \mathrm{~h}(p=0.37)$ after conditioning. They did not differ from winter bees in their responses to the conditioned odour or to the new odour $5 \mathrm{~min}$ or $24 \mathrm{~h}$ after conditioning ( 5 min CS: $p=1.00,5$ min new odour: $p=0.17,24 \mathrm{~h}$ CS: $p=1.0,24$ h new odour: $\left.p=0.68, n_{\text {summer foragers }}=10\right)$. But similar 


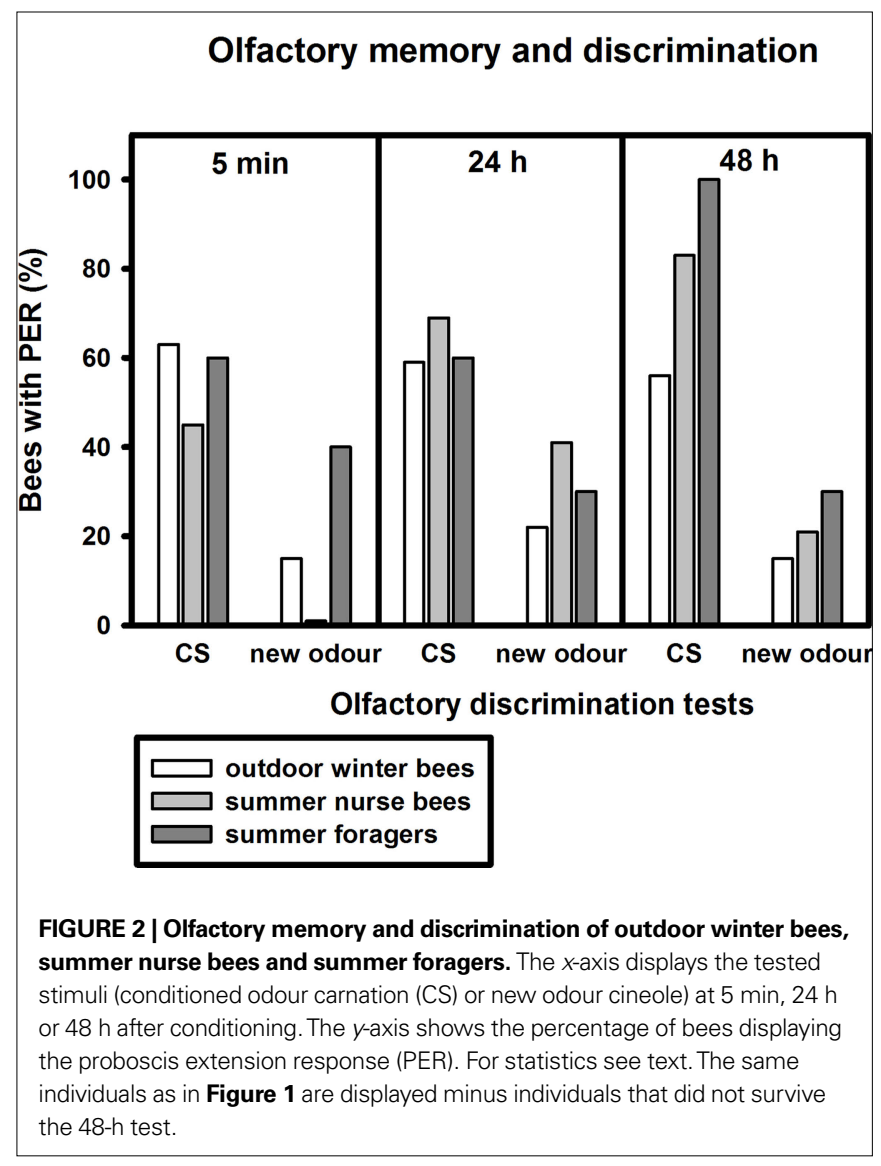

to nurse bees, foragers displayed a significantly stronger long-term memory $48 \mathrm{~h}$ after conditioning than winter bees $(p \leq 0.05)$, while not differing in their responses to the new odour $(p=0.36$, Fisher Exact Probability Test).

\section{TACTILE ACQUISITION AND GUSTATORY RESPONSIVENESS OF OUTDOOR WINTER BEES AND SUMMER BEES}

Similar to olfactory PER conditioning, winter bees showed a tactile learning curve which was comparable to that of summer nurse bees or summer foragers (Figure 3B). Tactile acquisition scores did not differ between outdoor winter bees and nurse bees or foragers which were tested in the summer (Figure 3D; $H=3.01, p=0.26$, $n_{\text {summer nurse bees }}=34, n_{\text {summer foragers }}=48, n_{\text {outdoor winter bees }}=44$, KruskalWallis $H$ Test). These data show that winter bees in principle did not differ in their tactile acquisition performance from summer bees with different social roles.

Because individual tactile learning performance is strongly dependent on gustatory responsiveness (for review see Scheiner et al., 2004), we also compared this factor between the groups. The sucrose-concentration response curve of winter bees was very similar to that of summer foragers (Figure 3A). As before, gustatory response scores differed overall between the three groups (Figure 3C; $H=6.15, p \leq 0.05$, Kruskal-Wallis $H$ Test). However, winter bees did not differ significantly in their GRS from summer nurse bees $(p>0.05)$ or from summer foragers $(p>0.05)$. But summer foragers were significantly more responsive than summer nurse bees ( $p \leq 0.05$, Dunn's Test).

\section{TACTILE MEMORY AND DISCRIMINATION OF OUTDOOR WINTER BEES} AND SUMMER BEES

After training, conditioned winter bees showed significant discrimination between the conditioned vertical pattern and a new horizontal pattern $5 \mathrm{~min}$ and $48 \mathrm{~h}$ after training, but not $24 \mathrm{~h}$ after conditioning (Figure 4; $5 \mathrm{~min}: p \leq 0.05,24 \mathrm{~h}: p=0.13$, 48 h: $p \leq 0.01, n_{\text {winter bees }}=44$, Fisher Exact Probability Test). In contrast to olfactory conditioning, the bees showed a significant decline in conditioned responses to the vertical pattern between $5 \mathrm{~min}$ and $24 \mathrm{~h}$ after training ( $p \leq 0.05$, Fisher Exact Probability Test).

Of the bees surviving the 48-h memory tests, nurse bees displayed significant tactile discrimination $5 \mathrm{~min}$ and $24 \mathrm{~h}$ after conditioning ( 5 min: $p \leq 0.05,24 \mathrm{~h}: p \leq 0.05$ ) but not $48 \mathrm{~h}$ after conditioning $(p=1.00)$. Winter bees did not differ from summer nurse bees in their responses to the conditioned pattern or to the new pattern at all test points after conditioning (Figure 4; 5 min CS: $p=0.16$, new pattern: $p=0.06,24$ h CS: $p=0.32$, new pattern: $p=1.00,48 \mathrm{~h}$ CS: $p=0.31$, new pattern: $p=0.54, n_{\text {outdoor winter bees }}=44, n_{\text {summer nurse bees }}=29$, Fisher Exact Probability Test).

Similar to the nurse bees, surviving foragers displayed significant tactile discrimination $5 \mathrm{~min}$ and $24 \mathrm{~h}$ after conditioning (5 min: $p \leq 0.05,24 \mathrm{~h}: p \leq 0.05$ ) but not $48 \mathrm{~h}$ after conditioning $(p=0.49)$. Foragers did not differ significantly from winter bees in their responses to the conditioned pattern at all time points after conditioning. But they showed the trend to respond more often to the conditioned pattern in the mid-term and long-term memory tests $24 \mathrm{~h} 48 \mathrm{~h}$ after conditioning than winter bees (Figure 4; 5 min: $p=0.78,24 \mathrm{~h}: p=0.08,48 \mathrm{~h}: p=0.08, n_{\text {sum }}$ mer foragers $=17)$. In addition, foragers responded less often to the new pattern $48 \mathrm{~h}$ after conditioning, while not differing from winter bees in their responses to the new pattern in the earlier tests ( 5 min: $p=0.35,24 \mathrm{~h}: p=1.00,48 \mathrm{~h}: p \leq 0.05$, Fisher Exact Probability Test).

\section{OLFACTORY ACQUISITION AND GUSTATORY RESPONSIVENESS OF OUTDOOR WINTER BEES AND INDOOR WINTER BEES}

Outdoor winter bees normally do not have the chance to perform flights during the winter time, because of cold temperatures outside. The learning performance of foragers, however, generally decreases with increasing foraging duration (Behrends et al., 2007; Scheiner and Amdam, 2009). In addition, foraging activity leads to decreased stress resistance and accumulation of brain damage (Seehuus et al., 2006b). We therefore wanted to test if the opportunity to fly in the winter time reduced the learning performance of winter bees.

Indoor winter bees had the opportunity to fly at room temperature and to collect pollen, sucrose solution or water during the winter period. They were placed in a room maintained at constant $22^{\circ} \mathrm{C}$ and a light/dark cycle of $12 \mathrm{~h} / 12 \mathrm{~h}$. Despite these conditions, we hardly observed any breeding activity in this colony or in similar colonies maintained over different winter periods.

Indoor winter bees displayed a similar olfactory acquisition curve to that of outdoor winter bees (Figure 5B). Their olfactory acquisition scores did not differ significantly from that of outdoor winter bees (Figure 5D; $Z=1.18, p=0.24$, 


\section{A Gustatory responsiveness}

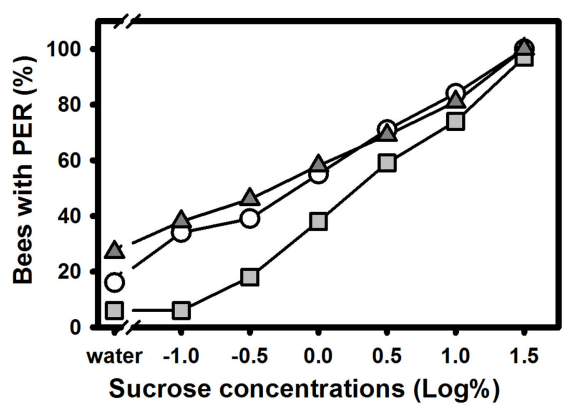

C

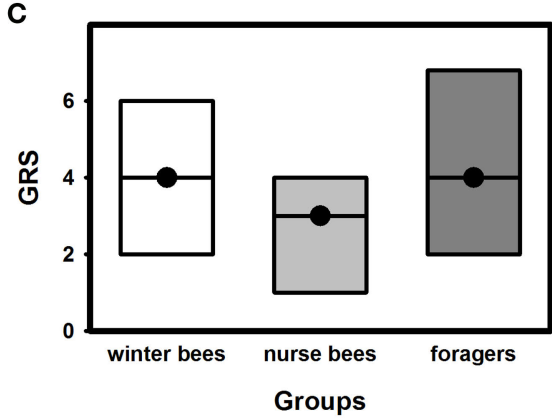

$-0-$ outdoor winter bees
$-\square-$ summer nurse bees
$-\triangle-$ summer foragers

FIGURE 3 | Gustatory responsiveness and tactile acquisition of outdoor winter bees, summer nurse bees and summer foragers.

(A) Sucrose-concentration response curves of outdoor winter bees, summers nurse bees and summer foragers. The $x$-axis displays the sucrose concentration offered to the antennae of each bee. The $y$-axis shows the percentage of bees showing the proboscis extension response (PER). (B) Tactile acquisition curves of outdoor winter bees, summers nurse bees and summer foragers. The $x$-axis displays the conditioning trials. The $y$-axis shows the percentage of bees

\section{B Tactile acquisition}
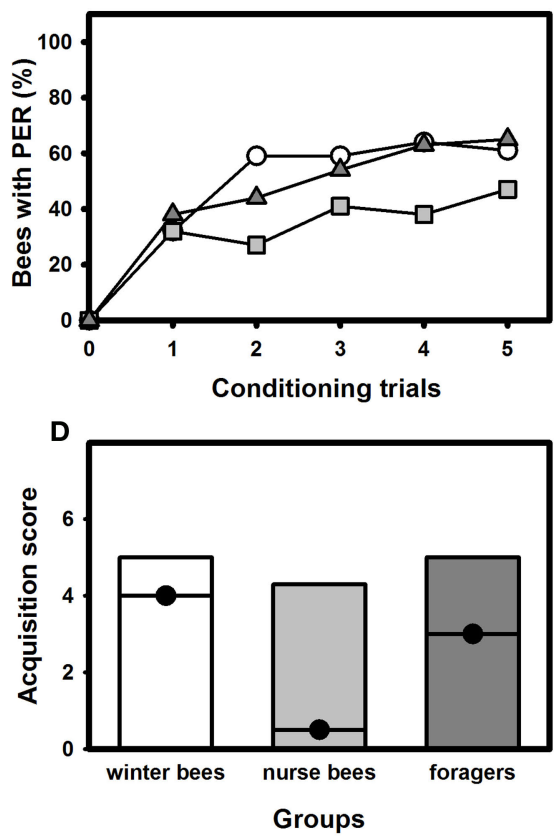

showing conditioned PER. (C) Gustatory response scores (GRS) of outdoor winter bees, summers nurse bees and summer foragers. The $x$-axis displays the different groups. The $y$-axis shows median GRS (dots) and 25\% (lower line) and 75\% (upper line) quartiles. (D) Tactile acquisition scores of outdoor winter bees, summers nurse bees and summer foragers. The $x$-axis displays the different groups. The $y$-axis shows median acquisition scores (dots) and 25\% (lower line) and 75\% (upper line) quartiles. $n_{\text {indoor winter bees }}=40 ; n_{\text {outdoor inter bees }}=30$, Mann-Whitney $U$ Test). However, indoor winter bees were more responsive to sucrose (Figure 5A), which was used as reward during conditioning. They had significantly higher gustatory response scores than respective outdoor winter bees (Figure 5C; $Z=2.69, p \leq 0.01$, Mann-Whitney $U$ Test).

As bees with higher GRS usually reach higher acquisition scores than bees with low GRS (Scheiner et al., 1999, 2001a,b, 2003), our data suggest that indoor winter bees displayed poorer acquisition than outdoor winter bees. This phenomenon becomes particularly apparent in bees with low gustatory responsiveness (GRS 1-2) or intermediate responsiveness (GRS 3-4). Despite equal responsiveness, outdoor winter bees in these GRS classes appeared to reach higher acquisition scores than respective indoor bees, although these differences were not statistically significant, probably due to the comparatively small sample sizes (data not shown). In individuals with high gustatory responsiveness (GRS classes 5-7), there was no such apparent difference in acquisition scores between indoor and outdoor winter bees (data not shown).

\section{OLFACTORY MEMORY AND DISCRIMINATION OF OUTDOOR WINTER BEES AND INDOOR WINTER BEES}

Of bees surviving the 48-h test, indoor winter bees demonstrated significant olfactory discrimination and long-term memory (Figure 6). Bees responded significantly more often to the conditioned odour carnation than to the new odour cineole $5 \mathrm{~min}(p \leq 0.05), 24 \mathrm{~h}$ $(p \leq 0.01)$ and $48 \mathrm{~h}(p \leq 0.01$, Fisher Exact Probability Test) after conditioning.

Outdoor winter bees did not differ from indoor winter bees in their responses to the conditioned odour or to the new odour at all test points after conditioning (Figure 6; 5 min CS: $p=0.58$, new pattern: $p=0.72,24 \mathrm{~h}$ CS: $p=1.00$, new pattern: $p=0.73$, 48 h CS: $p=0.78$, new pattern: $p=1.00, n_{\text {indoor winter bees }}=24, n_{\text {outdoor winter bees }}=24$; Fisher Exact Probability Test).

\section{DISCUSSION}

\section{LEARNING OF OUTDOOR WINTER BEES}

Our results demonstrate that winter bees show an average associative learning performance in classical olfactory conditioning (Figure 1) and operant tactile conditioning (Figure 3), despite their 


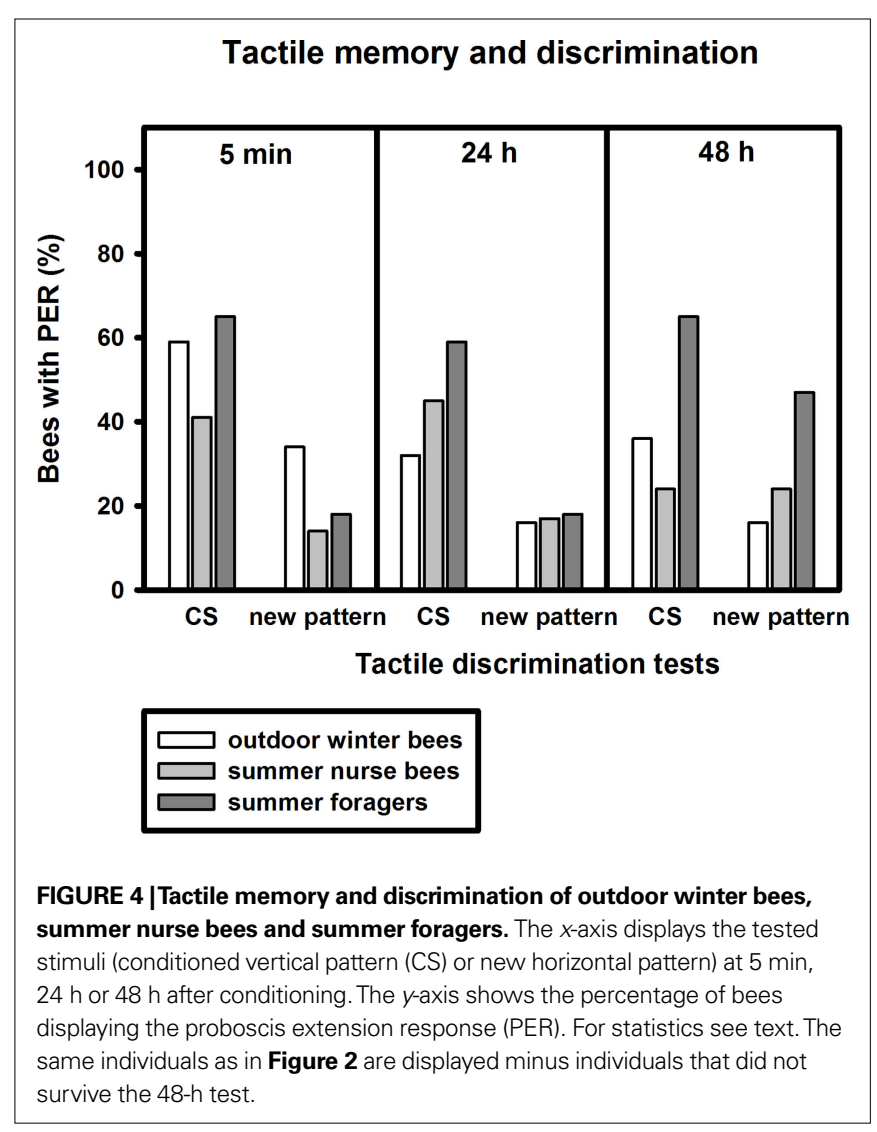

high chronological age. Tactile and olfactory acquisition scores of winter bees were very similar to those of summer foragers or summer nurse bees (Figure $\mathbf{2}$ for olfactory learning and Figure $\mathbf{4}$ for tactile learning), although the latter were much younger.

Naturally, learning performance of summer bees depends on a number of variables, like changes in nectar source profitability, in-hive conditions or changes in season (Scheiner et al., 2003). Therefore, the summer bees tested in our experiments might have differed from summer bees tested in another year or in another week of the same season. However, all of our earlier experiments demonstrate that individual gustatory responsiveness is the decisive determinant of associative learning performance in honey bees. Summer bees tested at different weeks of the foraging season, for example, do not differ in their learning performance, when they are equally responsive to gustatory stimuli tested with the proboscis extension response (Scheiner et al., 2003).

Our summer foragers and nurse bees did not differ from the tested winter bees in their gustatory response scores or in their associative learning performance. Therefore, our data imply that there are no fundamental differences in the relationship between sensory responsiveness and associative learning between winter and summer bees.

The learning abilities of outdoor winter honey bees are thus very different from a number of other insect species and vertebrates. In Drosophila melanogaster, for example, artificial selection for high life span led to low olfactory learning performance, implying a negative correlation between longevity and learning performance in this insect (Burger et al., 2008). In the American cockroach
(Periplaneta americana), experiments on a vision-based learning paradigm showed a negative relationship between age and learning performance (Brown and Strausfeld, 2009). Old mice were deficient in learning a discrimination reversal and different complex maze tasks, while performing normally in a simple spatial discrimination task (Warren, 1986).

The excellent learning and memory performance of outdoor winter bees suggests that their brains do not develop behavioural signs of cognitive senescence as active foragers do in the summer time. The latter typically display reduced acquisition in tactile and olfactory learning after foraging for more than 2 weeks (Behrends et al., 2007; Scheiner and Amdam, 2009). This is further evidence that in honey bees, chronological age does not affect cognitive functions in the same way as in most other species. The function of the individual in the hive (reduced-activity state in the hive or active foraging activity outside the hive) appears to be the decisive factor determining how fast a bee shows signs of senescence.

By which mechanisms winter bees are protected from cognitive senescence, however, remains unclear. According to the oxidative stress hypothesis of Harman (1956), cumulative oxidative damage causes ageing and a reduction of lifespan, whereas protection from oxidative damage increases life span. It is therefore conceivable that winter bees are protected from oxidative damage in the brain, leading to longer life span and protection from cognitive senescence. In some organisms, cognitive senescence has been attributed to signs of oxidative stress in the brain. In Caenorhabditis elegans, mutants with elevated oxidative stress levels displayed an impaired learning performance (Murakami and Murakami, 2005). In mice, Forster et al. (1996) showed that loss of cognitive function at high age is associated with oxidative protein damage.

Therefore, winter bees should have a lower rate of reactive oxygen species production than summer bees. Alternatively, winter bees should be more able to repair oxidative damage in the brain or to eliminate reactive oxygen species or to reduce the number of reactive oxygen species than summer bees. Corona et al. (2005) measured mRNA levels for eight antioxidant genes and five genes encoding mitochondrial proteins involved in cellular respiration in short-lived summer workers and queens, which live up 5 years (for review see Remolina and Hughes, 2008). Interestingly, levels of antioxidant mRNA in workers increased with age or did not change, whereas they decreased in queens. Therefore, differences in oxidative stress resistance alone seem unlikely to explain the longevity differences observed in honey bees, because summer foragers live much shorter than winter bees and queens.

Another study on oxidative stress comes from Seehuus et al. (2006b). The authors measured levels of oxidative carbonylation in the brain. They demonstrate that foragers have higher levels of oxidative carbonylation than nurse bees and that winter bees have lower levels of oxidative carbonylation than summer foragers. Therefore, oxidative stress tolerance could be one factor leading to exquisite acquisition and memory in winter bees, but other factors are certainly also involved.

One candidate for protecting winter bees from oxidative damage in the brain is vitellogenin, because winter bees have similar levels of vitellogenin as nurse bees (Fluri et al., 1982). Vitellogenin is an egg yolk precursor which is accumulated in nurse bees, because it is normally required for producing brood food. In addition, 


\section{A Gustatory responsiveness}

\section{B Olfactory acquisition}
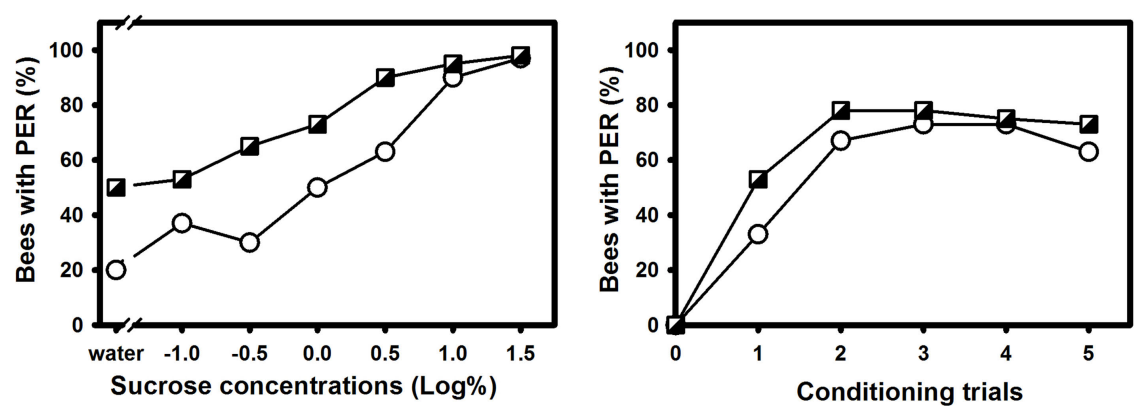

C
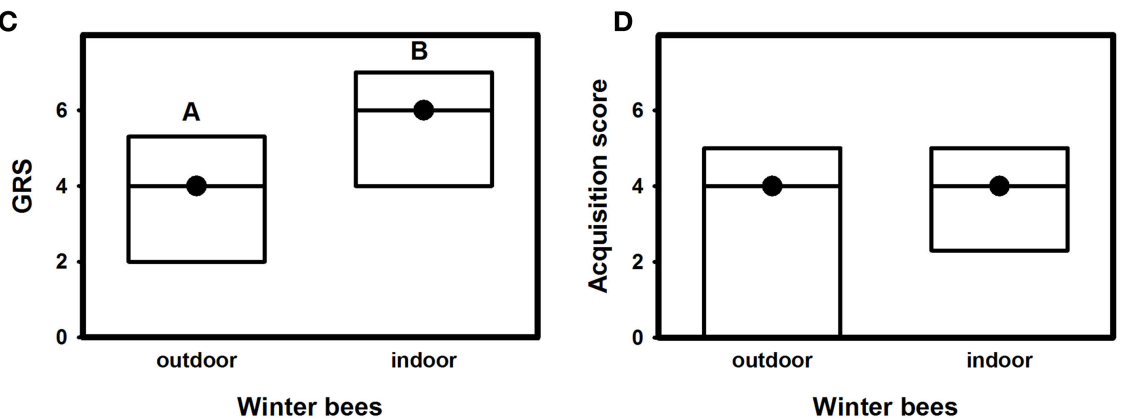

FIGURE 5 | Gustatory responsiveness and olfactory acquisition of outdoor winter bees and indoor winter bees. (A) Sucrose-concentration response curves of outdoor winter bees and indoor winter bees. The $x$-axis displays the sucrose concentration offered to the antennae of each bee. The $y$-axis shows the percentage of bees showing the proboscis extension response (PER). (B) Olfactory acquisition curves of outdoor winter bees and indoor winter bees. The $x$-axis displays the conditioning trials. The $y$-axis shows the percentage of bees showing conditioned PER. (C) Gustatory response

scores (GRS) of outdoor winter bees and indoor winter bees. The $x$-axis displays the different groups. The $y$-axis shows median GRS (dots) and 25\% (lower line) and 75\% (upper line) quartiles. Groups with different letters differ significantly from each other. For statistics see text. (D) Olfactory acquisition scores of outdoor winter bees and indoor winter bees. The $x$-axis displays the different groups. The $y$-axis shows median acquisition scores (dots) and $25 \%$ (lower line) and 75\% (upper line) quartiles. The outdoor winter bees were the same as in Figure 1.

vitellogenin is a potent antioxidant in the honey bee, protecting the brain from oxidative cell damage (Seehuus et al., 2006a). The neuroprotective properties of this protein may allow winter bees to survive the long winter period without severe brain damage. Furthermore, upstream effects of the vitellogenin gene, such as the maintenance of immune functions (Amdam et al., 2005) and its regulatory effects on juvenile hormone (Guidugli et al., 2005) may contribute to behavioural and physiological differences between stress-resistant winter bees and summer bees with lower stress resistance.

\section{FLIGHT ACTIVITY AND LEARNING PERFORMANCE}

Another possible explanation for the excellent learning performance and longevity of winter bees lies in their reduced flight activity. A number of experiments indicate that foragers are prompt to intrinsic mortality factors like energetic expenditure, physiological exhaust and mechanical senescence (Neukirch, 1982; Cartar, 1992; Crailsheim et al., 1996; Rueppell et al., 2007). In addition, foraging activity leads to high levels of oxidative stress in flight muscle tissue (Williams et al., 2008). The mean time used per one foraging trip increases when bees reach their 50th foraging trip (Tofilski, 2000). This decline in physical performance may also be associated with changes in learning performance.

To study whether foraging activity leads to a reduced associative learning performance we placed a small hive inside an indoor flight room at the end of the foraging season. The bees in this colony were encouraged to forage for water, sucrose solution or pollen. Their frequent flight activity apparently affected their associative learning performance and possibly their gustatory responsiveness. Although the indoor winter bees were more responsive to gustatory stimuli than the outdoor winter bees, they did not perform better in associative learning. Particularly indoor winter bees with low (GRS 1-2) or intermediate gustatory response scores (GRS 3-4) needed more trials for associating the odour with the sucrose reward than outdoor winter bees with the same gustatory responsiveness. Indoor winter bees with high gustatory scores, in contrast, did not differ in their learning performance from outdoor winter bees. This finding suggests differential effects of frequent flight activity on bees with different gustatory responsiveness. Whether increased flight activity itself led to a decrease in gustatory response scores is an 


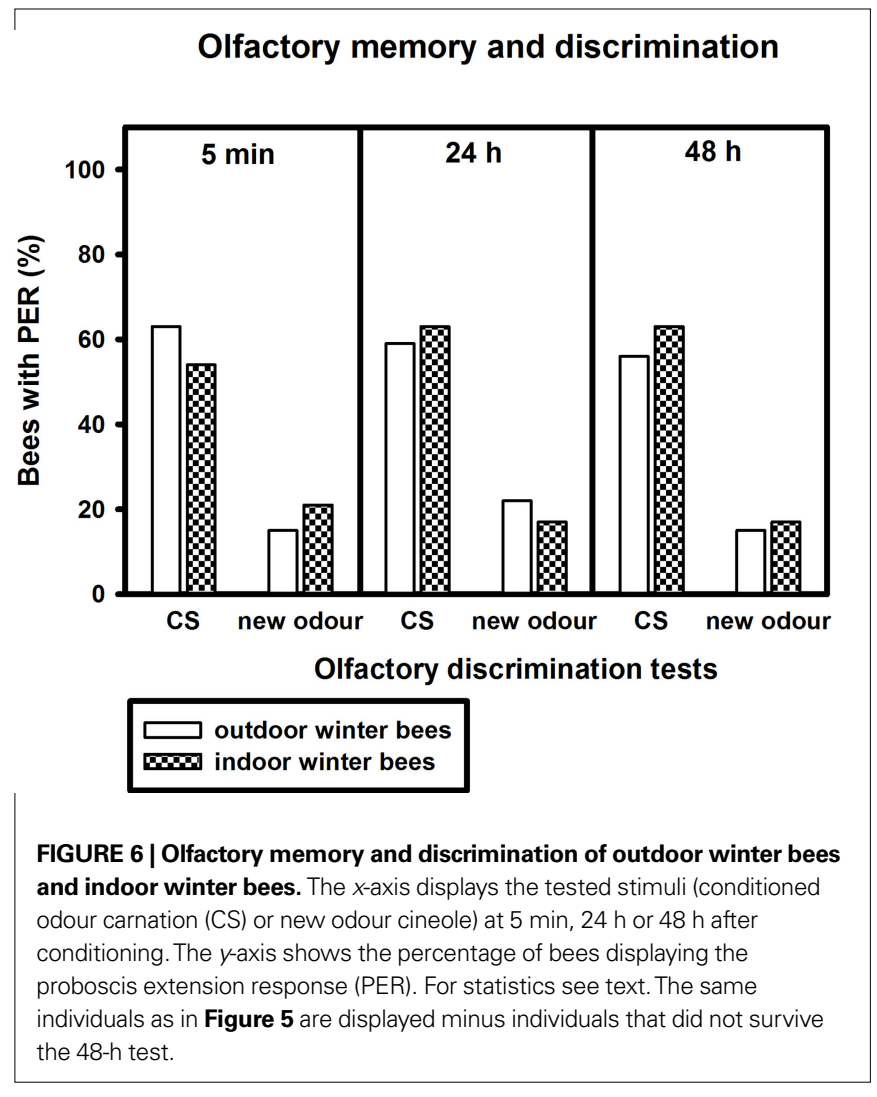

open question, because it is also conceivable that the climatic conditions in the flight room affected the gustatory responsiveness of the indoor winter bees. Another interesting question is whether individual differences in flight activity led to the observed differences in learning performance in bees with low or intermediate GRS.

\section{LONG-TERM MEMORY OF WINTER BEES}

Outdoor and indoor winter bees displayed a significant olfactory long-term memory. Forty-eight hours after conditioning, $56 \%$ of the trained outdoor winter bees and $63 \%$ of the indoor winter bees still showed conditioned proboscis extension when stimulated with the conditioned odour carnation. Nevertheless, nurse bees and foragers displayed a significantly better olfactory long-term memory than winter bees, suggesting an effect of chronological age on this form of long-term memory. But tactile long-term memory of winter bees did not differ significantly from that of summer nurse bees or foragers, although there was a similar trend observable between foragers and winter bees. These findings suggest differential effects of high chronological age on associative acquisition and memory. Long-term memory appears to be impaired, although only slightly, whereas acquisition appears normal in winter bees.

Winter bees thus behave opposite to summer foragers with long foraging duration. Although chronological age has no impact on associative learning in foragers, we found in an earlier study that foraging duration can severely impair associative acquisition in bees (Scheiner and Amdam, 2009). Although summer foragers with long foraging duration displayed an impaired acquisition, they had an extremely good long-term memory. These data are further support for the assumption that learning and memory systems are differentially affected by age and social role or foraging duration.

Although slightly impaired, winter bees can memorize the formed associations between odours, tactile patterns and a sucrose reward over days. In fact, winter bees are even capable of retaining a memory over several months, as shown by Lindauer (1963). In his experiments, winter bees remembered a food source from the previous autumn for a period of 173 days. Bees can even use olfactory experiences acquired inside the hive for later foraging decisions (Farina et al., 2007; Arenas et al., 2008; Grüter et al., 2009). An interesting question is whether winter bees trained to an odour in olfactory PER learning shortly before the winter season would remember this odour the following spring and would be able to transfer this memory to the field.

The capability of forming an extreme long-term memory over the winter period is not restricted to honey bees. A similarly longlasting spatial form of memory of nest location was demonstrated in red wood ants which stayed underground during a hibernation period of about 210 days (Rosengren and Fortelius, 1986). In marmots (Marmota marmota), long-term memory was also not affected by a hibernation period of 6 months (Clemens et al., 2009). However, it needs to be stressed that winter bees do not spend the cold period in hibernation but remain active inside the hive.

\section{DISCRIMINATION OF WINTER BEES}

Winter bees showed significant discrimination between the conditioned odour carnation and the new odour cineole, regardless of whether they spent the winter confined to the hive or with the opportunity to fly about in a flight room. Discrimination between conditioned and new tactile stimuli was also apparent, although winter bees discriminated better between the odours. This finding is well in line with earlier studies demonstrating that discrimination of olfactory cues appears to be less difficult for honey bees than discrimination of tactile cues (Scheiner et al., 2003). It also shows that winter bees are capable of forming exact memories when associating odours or tactile cues with a sucrose reward. Their discrimination abilities did not differ from those of summer nurse bees or foragers. This, in turn, implies that winter bees have no deficits in their olfactory system or in their antennal motor system, despite their high chronological age. However, to answer this question in more detail, experiments analysing the odour perception and processing and the uptake of tactile information while scanning a plate are required.

\section{CONCLUSIONS}

Our study shows in insects that high chronological age does not necessarily lead to a severe decline in cognitive functions such as associative acquisition, discrimination or memory. Although extremely old, winter bees displayed normal olfactory and tactile acquisition and discrimination and slightly impaired olfactory long-term memory. This is in sharp contrast to the learning behaviour of many vertebrate and some other insect species. The honey bee thus has the potential of serving as a new model organism for studying mechanisms preventing the ageing brain from cognitive senescence.

\section{ACKNOWLEDGMENTS}

We would like to thank Benedikt Polaczek for his excellent beekeeping and the two anonymous reviewers for their helpful and productive comments. 


\section{REFERENCES}

Amdam, G. V., Aase, A. L., Seehuus, S. C., Fondrk, K. M., Norberg, K., and Hartfelder, K. (2005). Social reversal of immunosenescence in honey bee workers. Exp. Gerontol. 40, 939-947.

Amdam, G. V., and Page, R. E. (2005). Intergenerational transfers may have decoupled physiological and chronological age in a eusocial insect. Ageing Res. Rev. 4, 398-408.

Arenas, A., Fernandez, V., and Farina, W. M. (2008). Floral scents experienced within the colony affect long-term foraging preferences in honeybees. Apidologie 39, 714-722.

Behrends, A., Scheiner, R., Baker, N., and Amdam, G.V. (2007). Cognitive aging is linked to social role in honey bees (Apis mellifera). Exp. Gerontol. 42, 1146-1153.

Bitterman, M.E., Menzel, R., Fietz,A., and Schäfer, S. (1983). Classical conditioning of proboscis extension extension in honeybees (Apis mellifera). J. Comp. Physiol. 97, 107-119.

Brown, S., and Strausfeld, N. (2009). The effect of age on a visual learning task in the American cockroach. Learn. Mem. 16, 210-222.

Burger, J. M., Kolss, M., Pont, J., and Kawecki, T. J. (2008). Learning ability and longevity: a symmetrical evolutionary trade-off in Drosophila. Evolution 62, 1294-1304.

Cartar, R.V. (1992). Morphological senescence and longevity: an experiment relating wing wear and life span in foraging wild bumble bees. J. Anim. Ecol. 61, 225-231.

Chung, K. K., Dawson, V. L., and Dawson, T. M. (2003). New insights into Parkinson's disease. J. Neurol. 3, 15-24.

Clemens, L. E., Heldmaier, G., and Exner, C. (2009). Keep cool: memory is retained during hibernation in Alpine marmots. Physiol. Behav. 98, 78-84.

Corona, M., Hughes, K. A., Weaver, D. B., and Robinson, G. E. (2005). Gene expression patterns associated with queen honey bee longevity. Mech. Ageing Dev. 126, 1230-1238.

Crailsheim, K., Hrassnigg, N., and Stabentheiner, A. (1996). Diurnal behavioural differences in forager and nurse honey bees (Apis mellifera carnica Pollm). Apidologie 27, 235-244.

Erber, J., Pribbenow, B., Grandy, K., and Kierzek, S. (1997). Tactile motor learning in the antennal system of the honeybee (Apis mellifera L.). J. Comp. Physiol. A 181, 355-365.

Farina, W. M., Grüter, C., Acosta, L. E., and McCabe, S. (2007). Honeybees learn floral odors while receiving nectar from foragers within the hive. Naturwissenschaften 94, 55-60.
Fluri, P., Lüscher, M., Wille, H., and Gerig, L. (1982). Changes in weight of the pharyngeal gland and haemolymph titres of juvenile hormone, protein and vitellogenin in worker honey bees. $J$. Insect Physiol. 28, 61-68.

Forster, M. J., Dubey, A., Dawson, K. M. Stutts, W. A., Lal, H., and Sohal, R. S. (1996).Age-related losses of cognitive function and motor skills in mice are associated with oxidative protein damage in the brain. Proc. Natl. Acad. Sci. U. S. A. 93, 4765-4769.

Giurfa, M. (2007). Behavioral and neural analysis of associative learning in the honeybee: a taste from the magic well. J. Comp. Physiol. A 193, 801-824.

Giurfa, M., Fabre, E., Flaven-Pouchon, J., Groll, H., Oberwallner, B., Vergoz, V., Roussel, E., and Sandoz, J. C. (2009). Olfactory conditioning of the sting extension reflex in honeybees: memory dependence on trial number, interstimulus interval, intertrial interval, and protein synthesis. Learn. Mem. 16, 761-765.

Giurfa, M., and Malun, D. (2004) Associative mechanosensory conditioning of the proboscis extension reflex in honeybees. Learn. Mem. 11, 294-302.

Gower, A. J., and Lamberty, Y. (1993). The aged mouse as a model of cognitive decline with special emphasis on studies in NMRI mice. Behav. Brain Res. 57, 163-173.

Grotewiel, M. S., Martin, I., Bhandari, P., and Cook-Wiens, E. (2005). Functional senescence in Drosophila melanogaster. Ageing Res. Rev. 3, 372-397.

Grüter, C., Balbuena, M. S., and Farina, W. M. (2009). Retention of long-term memories in different age groups of honeybee (Apis mellifera) workers. Insectes Soc. 56, 385-387.

Guidugli, K. R., Nascimento, A. M., Amdam, G. V., Barchuk, A. R., Omholt, S., Simões, Z. L., and Hartfelder, K. (2005). Vitellogenin regulates hormonal dynamics in the worker caste of a eusocial insect. FEBS Lett. 579, 4961-4965.

Guzmán-Novoa, E., Page, R. E., and Gary, N. E. (1994). Behavioral and life-history components of division of labor in honey bees (Apis mellifera L.). Behav. Ecol. Sociobiol. 34, 409-417.

Harman, D. (1956). Aging: a theory based on free radical and radiation chemistry. J. Gerontol. 11, 298-300.

Huang, Z.-Y., and Robinson, G. E. (1996). Regulation of honey bee division of labor by colony age demography. Behav. Ecol. Sociobiol. $39,147-158$.
Keller, L., and Jemielity, S. (2006). Social insects as a model to study the molecular basis of ageing. Exp. Gerontol. 41 , 553-556.

Kuwabara, M. (1957). Bildung des bedingten Reflexes von Pavlovs Typus bei der Honigbene, Apis mellifica. J. Fac. Sci. Hokkaido Univ. Zool. 13 458-464.

Lindauer, M. (1963). Allgemeine Sinnesphysiologie, Orientierung im Raum. Fortschr. Zool. 16, 58-140.

Menzel, R., and Müller, U. (1996). Learning and memory in honeybees: from behavior to neural substrates. Rev. Neurosci. 19, 379-404.

Murakami, S., and Murakami, H. (2005) The effects of aging and oxidative stress on learning behavior in C. elegans. Neurobiol. Aging 26, 899-905.

Neukirch, A. (1982). Dependence of the life span of the honeybee (Apis mellifera) upon flight performance and energy consumption. J. Comp. Physiol. 146, 35-40.

Omholt, S. W., and Amdam, G. V. (2004) Epigenetic regulation of aging in honeybee workers. Sci. Aging Knowledge Environ. 26, pe28.

Page, R. E., and Peng, C. Y. S. (2001) Aging and development in social insects with emphasis on the honey bee, Apis mellifera L. Exp. Gerontol. 36, 695-711.

Remolina, S.C., and Hughes, K.A. (2008). Evolution and mechanisms of long life and high fertility in queen honey bees. Age (Omaha) 30, 177-185.

Robinson, G. E., Page, R. E., Strambi, C. and Strambi,A. (1989). Hormonal and genetic control of behavioral integration in honeybee colonies. Science 246 109-112.

Robinson, G. E., Page, R. E., Strambi, C. and Strambi, A. (1992). Colony integration in honey bees: mechanism of behavioral reversion. Ethology 90 336-348.

Rosengren, R., and Fortelius, W. (1986) Ortstreue in foraging ants of the Formica rufa group. Hierarchy of orienting cues and long-term memory. Insect Soc. 33, 306-337.

Rueppell, O., Amdam, G. V., Page, R. E., and Carey, J. R. (2004). From genes to societies. Sci.Aging Knowledge Environ. 5 , pe5.

Rueppell, O., Christine, S., Mulcrone, C. and Groves, L. (2007). Aging without functional senescence in honey bee workers. Curr. Biol. 17, R274-R275.

Rueppell, O., Kaftanouglu, O., and Page, R. E. (2009). Honey bee (Apis mellifera) workers live longer in small than in large colonies. Exp. Gerontol. 44 447-452.

Rueppell, O., Linford, R., Gardner, P., Coleman, J., and Fine, K. (2008).
Aging and demographic plasticity in response to experimental age structures in honeybees (Apis mellifera $\mathrm{L}$ ). Behav. Ecol. Sociobiol. 62, 1621-1631.

Scheiner, R., and Amdam, G. V. (2009). Impaired tactile learning is related to social role in honeybees. J. Exp. Biol. 212, 994-1002.

Scheiner, R., and Arnold, G. (2010). Effects of patriline on gustatory responsiveness and olfactory learning in honey bees. Apidologie 41, 29-37.

Scheiner, R., Barnert, M., and Erber, J. (2003).Variation in water and sucrose responsiveness during the foraging season affects proboscis extension learning in honey bees. Apidologie 34, 67-72.

Scheiner, R., Erber, J., and Page, R. E. (1999). Tactile learning and the individual evaluation of the reward in honey bees (Apis mellifera L.). J. Comp. Physiol. A 185, 1-10.

Scheiner, R., Kuritz-Kaiser, A., Menzel, R., and Erber, J. (2005). Sensory responsiveness and the effects of equal subjective rewards on tactile learning and memory of honeybees. Learn. Mem. 12, 626-635.

Scheiner, R., Page, R. E., and Erber, J. (2001a). Responsiveness to sucrose affects tactile and olfactory learning in preforaging honey bees of two genetic strains. Behav. Brain Res. 120, 67-73.

Scheiner, R., Page, R. E., and Erber, J. (2001b). The effects of genotype, foraging role and sucrose perception on the tactile learning performance of honey bees (Apis mellifera L.). Neurobiol. Learn. Mem. 76, 138-150.

Scheiner, R., Page, R. E., and Erber, J. (2004). Sucrose responsiveness and behavioral plasticity in honey bees (Apis mellifera). Apidologie 35, 133-142.

Schulz, D. J., Sullivan, J. P., and Robinson, G. E. (2002). Juvenile hormone and octopamine in the regulation of division of labor in honey bee colonies. Horm. Behav. 42, 222-231.

Seehuus, S. C., Norberg, K., Gimsa, U., Krekling, T., and Amdam, G. V. (2006a). Reproductive protein protects functionally sterile honey bee workers from oxidative stress. Proc. Natl. Acad. Sci. U. S. A. 103, 962-967.

Seehuus, S. C., Krekling, T., and Amdam, G. V. (2006b). Cellular senescence in honey bee brain is largely independent of chronological age. Exp. Gerontol. 41, 1117-1125.

Seeley, T. D. (1995). The Wisdom of the Hive. Cambridge, MA: Harvard University Press.

Srinivasan, M. (2010). Honey bees as model for vision, perception, and cognition. Annu. Rev. Entomol. 55, 267-284. 
Tamura, T., Chiang, A. S., Ito, N., Liu, H. P., Horiuchi, J., Tully, T., and Saitoe, M. (2003). Aging specifically impairs amnesiac-dependent memory in Drosophila. Neuron 40, 1003-1011.

Tofilski, A. (2000). Senescence and learning in honeybee (Apis mellifera) workers. Acta Neurobiol. Exp. (Wars) 60, 35-39.

Unno, K., Takabayashi, F., Yoshida, H., Choba, D., Fukutomi, R., Kikunaga, N., Kishido, T., Oku, N., and Hoshino, M. (2007). Daily consumption of green tea catechin delays memory regression in aged mice. Biogerontology 8, 89-95.

Warren,J.M. (1986).Appetitive learning by old mice. Exp. Aging Res. 12, 99-105.

Williams, J. B., Roberts, S. P., and Elekonich, M. M. (2008). Age and natural metabolically-intensive behavior affect oxidative stress and antioxidant mechanisms. Exp. Gerontol. 43, 538-549.

Wilson, R. S., Arnold, S. E., Schneider, J. A., Boyle, P. A., Buchman, A. S., and Bennett, D. A. (2009). Olfactory impairment in presymptomatic
Alzheimer's disease. Ann. N.Y. Acad. Sci. 1170, 730-735.

Winston, M. L. (1987). The Biology of the Honey Bee. Cambridge, MA: Harvard University Press.

Conflict of Interest Statement: The authors declare that the research was conducted in the absence of any commercial or financial relationships that could be construed as a potential conflict of interest.

Received: 02 March 2010; paper pending published: 11 March 2010; accepted: 24
March 2010; published online: 13 April 2010.

Citation: Behrends $A$ and Scheiner $R$ (2010) Learning at old age: a study on winter bees. Front. Behav. Neurosci. 4:15. doi: 10.3389/fnbeh.2010.00015

Copyright (C) 2010 Behrends and Scheiner. This is an open-access article subject to an exclusive license agreement between the authors and the Frontiers Research Foundation, which permits unrestricted use, distribution, and reproduction in any medium, provided the original authors and source are credited. 